\title{
BMJ Open Improving decision making in acute healthcare through implementation of an intensive care unit (ICU) intervention in Australia: a multimethod study
}

\author{
Robyn Clay-Williams, ${ }^{\oplus 1}$ Brette Blakely, ${ }^{2}$ Paul Lane, ${ }^{3}$ Siva Senthuran, ${ }^{3}$ \\ Andrew Johnson ${ }^{3}$
}

To cite: Clay-Williams $R$, Blakely B, Lane P, et al. Improving decision making in acute healthcare through implementation of an intensive care unit (ICU) intervention in Australia: a multimethod study. BMJ Open 2019;9:e025041. doi:10.1136/ bmjopen-2018-025041

- Prepublication history and additional material for this paper are available online. To view these files, please visit the journal online (http://dx.doi. org/10.1136/bmjopen-2018025041).

Received 27 June 2018 Revised 26 November 2018 Accepted 6 February 2019

D) Check for updates

(C) Author(s) (or their employer(s)) 2019. Re-use permitted under CC BY-NC. No commercial re-use. See rights and permissions. Published by BMJ.

${ }^{1}$ Australian Institute of Health Innovation, Macquarie University, Sydney, New South Wales, Australia

${ }^{2}$ Australian Institute of Health Innovation, Macquarie University, Sydney, New South Wales, Australia

${ }^{3}$ Townsville Hospital and Health Service, Townsville, Queensland, Australia

Correspondence to Dr Robyn Clay-Williams; robyn.clay-williams@mq.edu.au

\section{ABSTRACT}

Objective To evaluate the implementation of an intensive care unit (ICU) intervention designed to establish rules for making ICU decisions about postsurgery beds.

Design Preintervention/postintervention case study using a multimethod approach, involving two phases of staff interviews, process mapping and collection of administrative data.

Setting ICU in a 700-bed regional tertiary care hospital in Australia.

Participants 31 interview participants. Phases 1 and 2 participants drawn from three groups of staff: bedside nursing staff in the ICU, ICU specialist doctors and senior management staff involved in oversight of ICU operations. Phase 2 included an additional participant group: staff from surgery and emergency departments. Intervention Implementation of an ICU escalation plan and introduction of a multidisciplinary morning meeting to determine ICU bed status in accordance with the plan. Main outcome measures Interview data consisted of preintervention staff perceptions of ICU workplace cohesiveness with bed pressure, and postintervention staff perceptions of the escalation plan and ICU performance. Administrative data consisted of bed status (red, amber or green), monthly number of planned elective surgeries requiring an ICU bed and monthly number of elective surgeries cancelled due to unavailability of ICU beds. Results Improved internal communication, decision making and cohesion within the ICU and better coordination between ICU and other hospital departments. Significant reduction in elective surgeries cancelled due to unavailability of ICU beds, $\chi^{2}=24.9, p<0.0001$.

Conclusions By establishing rules for decision making around ICU bed allocation, the intervention improved internal professional relationships within the ICU as well as between the ICU and external departments and reduced the number of elective surgeries cancelled.

\section{INTRODUCTION}

Targets to reduce elective surgery waiting lists are prevalent in Organization for Economic Co-operation and Development (OECD) countries, ${ }^{2}$ and various interventions have been explored to reduce waiting times. ${ }^{3}$
Strengths and limitations of this study

- This is a multimethod study, which allows us to understand why the intervention worked in addition to how well it worked.

- Data from a single intensive care unit (ICU) case may limit the generalisability of the findings.

- Drivers of patient population other than elective surgery that impact ICU bed capacity (such as emergency department factors) were not considered as part of our study.

In Australia, although the National Elective Surgery Target (NEST) is an important component of hospital performance measurement, ${ }^{4}$ median waiting times for elective surgery have increased by around $2 \%$ per year over the 5 years. ${ }^{5}$ As the population ages, more patients require access to high levels of care following surgery to assist their recovery ${ }^{6}$; this increasing demand on intensive care unit (ICU) beds places pressure on ICU clinicians and managers and has been shown to adversely impact patient safety. ${ }^{7-9}$ Internationally, we know that patients who require acute care following surgery are at higher risk of having their surgery cancelled. ${ }^{1011}$ Safety in healthcare remains problematic despite concerted efforts to understand why errors occur and to place protective barriers in place. ${ }^{12}$

In the ICU, there can be large and unexpected variation in requirement for beds, yet the cost of resources required to maintain continuous capacity for peak load are unduly prohibitive. The presence of uncontrolled variation makes the ICU unsuitable for standard improvement approaches that are based on identifying and fixing individual problems. A new concept focusing on resilience engineering $(\mathrm{RE})^{13}$ has the potential to improve patient safety by reversing the focus 


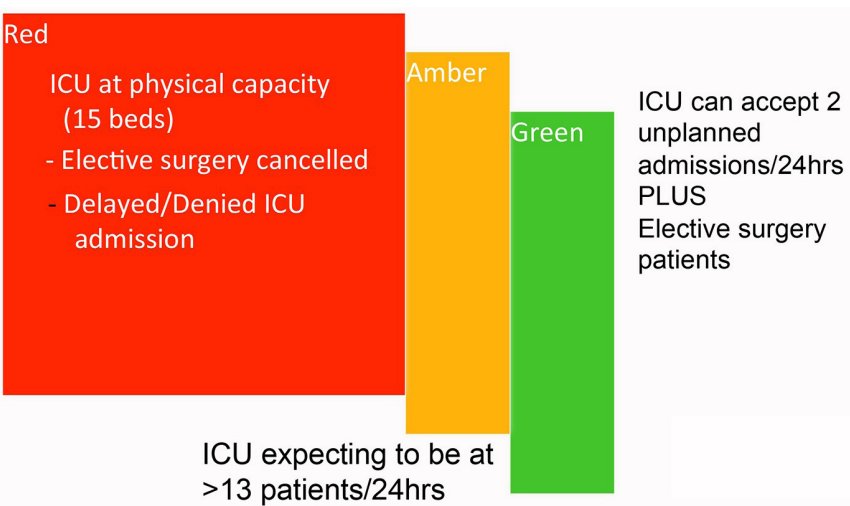

Figure 1 The ICU escalation plan. ICU, intensive care unit.

from being problem centric to looking at ways to improve functioning through positive measures that enhance system performance under all conditions. A resilient system can allow safety to occur even at 'the edge of chaos' when the system is strained beyond equilibrium. ${ }^{13}$ Research conducted internationally has shown potential for improved decision making and efficiency through planning and fostering resilient behaviour traits. ${ }^{14}$

The study was set in a busy, high-functioning, 700-bed tertiary care hospital in regional Australia. The ICU consisted of 14 adult beds and operated as a 'closed' ICU whereby medical and postsurgical patients were admitted under care of intensivists. Frequent late decisions to cancel elective surgery at short notice, due to lack of ICU beds, resulted in poor interdepartmental relations with emergency and surgery departments and overt conflict between clinicians in the ICU. This conflict between departments called for a positive approach that could improve an already well-performing unit, rather than a traditional approach of investigation of failure, such as root cause analysis.

\section{Description of the intervention}

RE principles ${ }^{15}$ were used to develop and implement a process to establish rules for making ICU decisions about postsurgery beds and to improve relationships between the surgery department and the ICU. A small team of influential clinical leaders in the hospital executive team and ICU had been in discussion over a number of years on how to implement RE in the hospital and concluded that encouraging cohesion, plus 'a few simple rules' to guide behaviour, would provide a starting point. By the terms 'cohesion' or 'cohesiveness', we mean the degree to which staff respect each other and work together in pursuit of the common goal of patient care. The intervention consisted of implementation of 'a few simple rules' in the form of an ICU escalation plan (overview at figure 1; detail, including clinician roles and responsibilities associated with the colour of the ICU bed status, at online appendix 1), and introduction of a mechanism to improve cohesion in the form of a multidisciplinary morning meeting, led by the senior consultant on duty, to determine ICU status in accordance with the plan. The
ICU escalation plan and associated morning meeting were developed by senior ICU staff over a number of months and implemented by the ICU director with agreement of senior ICU clinicians on a specified date. Prior to the intervention, the ICU had satisfactory performance metrics in comparison with similar hospitals, when measured in terms of length of stay, mortality, bedside handover, Australian and New Zealand Intensive Care Society Adult Patient Database comparative performance and trainee performance.

\section{METHOD}

The aim of the study was to evaluate the implementation of the ICU intervention, which was designed to improve decision making around bed allocation and cohesion in the ICU and relationships between the ICU and surgery department. The study used a multimethod approach, involving two phases of staff interviews, process mapping and collection of administrative data. Process mapping was completed using the Functional Resonance Analysis Method and is reported elsewhere. ${ }^{16}$

Phase 1 early implementation semistructured interviews were conducted to collect staff perceptions of ICU workplace cohesiveness with bed pressure. Interview participants were drawn from three groups of staff: bedside nursing staff in the ICU, ICU specialist doctors and senior management staff involved in oversight of ICU operations. Phase 2 interviews were conducted to collect postimplementation staff perceptions of the plan and ICU performance. Interview participants were drawn from four groups of staff: bedside nursing staff in the ICU, ICU specialist doctors, staff from surgery and emergency departments and senior management staff involved in oversight of ICU operations. Staff members from surgery and emergency departments were included in the phase 2 interviews to provide additional insight into how the escalation plan was perceived by those who interfaced regularly with the ICU. Interview schedule is at online appendix 2.

Standard ICU administrative data that are currently collected were obtained for the 11 months preintervention and 12 months throughout and postintervention. Only non-identifiable, aggregate data were obtained. Administrative data consisted of monthly number of planned elective surgeries requiring an ICU bed and monthly number of elective surgeries cancelled due to unavailability of ICU beds. During intervention and postintervention, data were also collected on whether the bed status was at 'red', 'amber' or 'green'.

\section{Qualitative analysis}

Inductive interpretive analysis ${ }^{17}$ of transcribed interviews was undertaken to identify key themes relating to the implementation of the escalation plan. Inductive interpretive analysis does not set out to test an hypothesis but instead seeks to produce an understanding of a phenomenon including how it is influenced by context and 
surrounding social constructs. Coding the data allows it to be organised and used to explore connections between data elements and to develop sets of concepts. Once coded, segments of data can be linked in a formal fashion to allow themes to emerge and to determine relationships that may exist between different data sets. This is a way of studying real world complex systems such as healthcare.

\section{Quantitative analysis}

Exploratory statistical analysis was conducted on ICU administrative data. On the advice of a biostatistician, $\chi^{2}$ analysis was chosen as the optimum method to compare the percentage of surgeries cancelled each month to the per cent of non-cancelled surgeries by month, before and after implementation of the intervention. Precategories and postcategories were compared with the data aggregated for all premonths and all postmonths.

\section{Patient and public involvement}

No patients or other members of the public were involved in this study.

\section{RESULTS}

\section{Qualitative: phase 1}

In phase 1, 12 hospital staff participated in semistructured interviews approximately 2 months after the plan commenced operation. Participants consisted of four doctors, four allied health professionals or nurses and four managers. Interviews were digitally recorded and professionally transcribed. Interview length averaged $26 \mathrm{~min}$ (range $11-50 \mathrm{~min}$ ). Data were coded by two researchers (RC-W and $\mathrm{BB}$ ), and discrepancies were resolved via discussion. Data saturation was reached.

Three themes emerged from inductive analysis: perceptions of the plan, benefits of the plan and processes associated with the morning meeting. Within each theme were a number of subthemes. Table 1 lists the themes and subthemes, along with example quotes.

Perceptions of the ICU plan were varied: 'It's a policy that's been written but it's more than just a policy ...' (phase 1 , doctor 1). Some participants felt that the plan was a behaviour contract or agreed process that negated the need for micro managing the bed state and resulted in reduced workload and fewer arguments: 'We don't have to fight about beds which is stressful' (phase 1, doctor 1). Others felt that the plan provided consistency and transparency. The ICU response is predictable, and all were aware of the big picture, which facilitated planning. It provided a more structured way of operating that participants felt was likely to improve patient flow.

The plan meant that additional ICU beds were available when on green for emergency or elective surgical admissions. While this was not very helpful to facilitate elective surgery that often required several days' notice, some saw the plan as a 'gesture of goodwill', signalling to surgery a willingness to cooperate. The plan also sent a signal to management that ICU are team players, and improvement oriented, and demonstrated willingness to take load off other departments.

Others felt the plan provided them with authority to say 'no'. It was perceived by some as providing a written 'line on the sand' and management endorsement of ICU refusal to accept patients when full. This levelled the power gradient between the ICU and surgery and between ICU and the Emergency Department (ED). Power gradients were perceived to be previously in favour of surgery and ED, as both of these departments had associated external performance targets (NEST and National Emergency Access Targets, respectively). While not a sure fix, the plan was perceived to provide visibility of the problem, and a common understanding of red/amber/ green status. Status colour could be used as a proxy for urgency or 'pay attention to my request' in a crisis.

The plan was also perceived as a 'canary in the coalmine' to identify system pressure. The status could be used as an indicator of proximal system operating point (see Cook and Rasmussen for further explanation ${ }^{13}$ ) and provided a record and trend information on ICU performance in meeting postsurgical needs and capacity.

Participants identified a number of perceived benefits of the intervention, including improved teamwork and communication. These benefits manifested as better information flow, better multidisciplinary team working and more coherent team mental models. Prior to the intervention, '... [when] we're full to capacity ... there was no written guideline on who to notify, what order it should be in and what to do...' (phase 1, manager 4). Standardised decision making led to clear ownership of problems. This resulted in less conflict within the ICU and better rapport with other hospital departments, leading to improved job satisfaction for ICU clinicians.

Participants also felt that the intervention resulted in new ways of thinking, including moving from a 'silos' to a 'systems' viewpoint. Clinicians started to think in terms of the 'system', and how patient flow is about the whole of hospital, not just the ICU or surgery or ED.

Creation of a multidisciplinary morning handover meeting at 08:00 appeared to facilitate information flow and improved team cohesion. Participants described the morning routine in the ICU prior to the intervention and explained how the new morning handover meeting functioned: preintervention, the ICU nurse unit manager (NUM) arrived at 07:00, checked bed state and advised surgery prior to first operation at $07: 30$. She then departed for the 08:45 hospital bed planning meeting at 08:30, passing ICU bed state information to the hospital bed planning team. The ICU consultants arrived around 08:30 and commenced handover ward rounds. Decisions on ICU discharges for that day were determined during the round, which may last several hours. Discharge information often conflicted with the NUM's earlier determination, resulting in short notice cancellation of surgeries and replanning by the hospital bed planning team (see figure 2A,B). The ultimate decision to cancel a surgical ICU bed flowed from the NUM to the executive director 
Table 1 Phase 1 themes and subthemes

\begin{tabular}{|c|c|c|}
\hline Theme & Subtheme & Example quotes \\
\hline \multirow[t]{4}{*}{$\begin{array}{l}\text { Perceptions of } \\
\text { the plan }\end{array}$} & A behaviour contract & $\begin{array}{l}\text { '... it is meant to provide agreement across disciplines ...' (Doctor } 1 \text { ) } \\
\text { '... everyone works within this policy ...' (Manager 4) } \\
\text {.... there was almost like rules of engagement and people knew how } \\
\text { decisions were made'. (Manager } 1 \text { ) }\end{array}$ \\
\hline & $\begin{array}{l}\text { Provides consistency, predictability } \\
\text { and transparency }\end{array}$ & $\begin{array}{l}\text { '... provide[s] guidance that's consistent so that our response is } \\
\text { consistent ...' (Doctor } 1 \text { ) } \\
\text { '... so it's completely clarified our entire process ...' (Manager 4) } \\
\text { '... we wanted it to be more transparent how beds get allocated ... } \\
\text { if we suddenly had a bus crash ... then we couldn't do our cardiac } \\
\text { surgery that wasn't because we were badly organised it's just } \\
\text { because we don't have that many beds'. (Doctor 2) }\end{array}$ \\
\hline & Gesture of goodwill & $\begin{array}{l}\text { 'I think [the Escalation Plan is] a good attempt at policy for (the) } \\
\text { ICU...' (Manager } 3 \text { ) } \\
\text { '[on GREEN] there are [ED, ward] patients that ... might not usually } \\
\text { come to ICU that we may admit with a lower threshold'. (Doctor 1) }\end{array}$ \\
\hline & $\begin{array}{l}\text { Not a fix, but provides visibility of the } \\
\text { problem }\end{array}$ & $\begin{array}{l}\text { '... flow doesn't always happen just because of the escalation plan. } \\
\text { Unfortunately, there are still bed blocked patients because the wards } \\
\text { are so full'. (AH/nurse 1) } \\
\text { 'It provides me with evidence if we're at capacity'. (Manager 4) } \\
\text { 'We say we're at RED or AMBER but I don't know if [those outside } \\
\text { ICU know exactly what that means] ...' (AH/nurse 1) }\end{array}$ \\
\hline $\begin{array}{l}\text { Benefits of the } \\
\text { plan }\end{array}$ & New ways of thinking & $\begin{array}{l}\text { 'I think the success of this ... it was able to give clinicians a different } \\
\text { way of looking at things ... the ability to think about your system, and } \\
\text { the safety of your system, I think is a real benefit... What I saw was } \\
\text { a shift in terms of the ... problem solving and some of the solution } \\
\text { finding'. (Manager 1) } \\
\text { 'The idea itself is beautiful. It had to happen'. (Manager 4) }\end{array}$ \\
\hline $\begin{array}{l}\text { Meeting } \\
\text { processes }\end{array}$ & No subthemes & $\begin{array}{l}\text { '...the nurses would go to the bed management meeting and the } \\
\text { doctors would not know what they'd asked for, how many beds they } \\
\text { had, how many nursing staff were available or how many people we } \\
\text { could admit. ...' (Doctor 2) }\end{array}$ \\
\hline
\end{tabular}

of the surgical department, frequently creating hostility and doctor-nurse conflict.

Postintervention, the ICU NUM arrived at the ICU at 07:00, checked bed state and advised surgery so that the operating theatre could commence at 07:30. The ICU consultants arrived for the new meeting at 08:00, where the multidisciplinary team of doctors, nurses and allied health professionals discussed who would be able to be discharged from the ICU that day. Decisions were agreed in time to postpone any scheduled surgery, and the NUM could present up to date information about ICU bed state to the hospital bed planning meeting at 08:30 (see figure $2 \mathrm{C}, \mathrm{D}$ ). Ultimately, ICU bed state was a shared decision by all ICU clinical staff on duty with recommendation, if required, to the executive director of surgery to cancel due to bed shortage. 
A

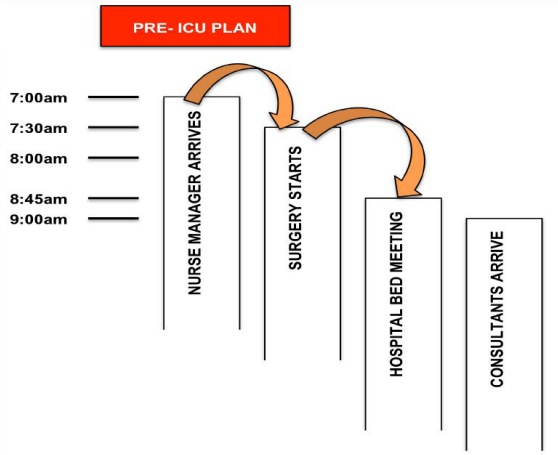

C

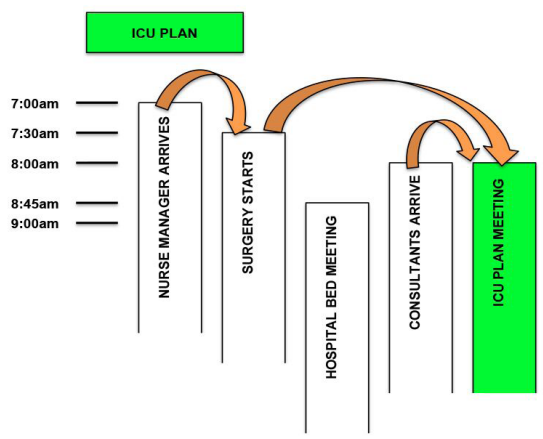

B

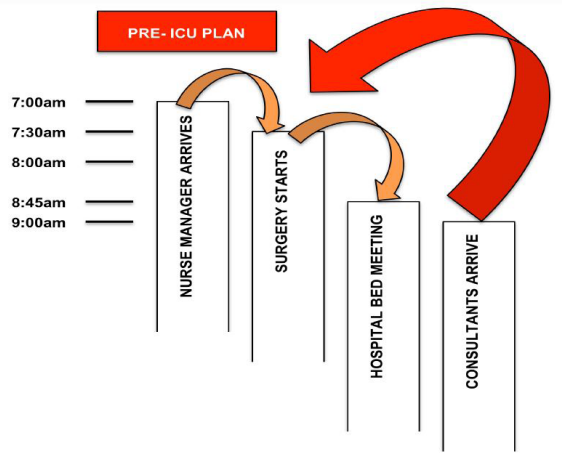

D



Figure 2 ICU bed state information flow. ICU, intensive care unit.

\section{Qualitative: phase 2}

In phase 2, 19 hospital staff participated in postimplementation semistructured interviews approximately 7 months after the plan commenced operation. Participants consisted of eight doctors, five allied health professionals or nurses and six managers. Interviews were digitally recorded and professionally transcribed. Interview length averaged $20 \mathrm{~min}$ (range $5-52 \mathrm{~min}$ ). Initial coding was completed by one researcher (BB) using NVivo software; themes were then grouped by two researchers (BB and RC-W) and refined via discussion. Data saturation was reached.

Seven months postimplementation, the key improvements in cohesion and communication found during phase 1 were further reinforced. The utility of the implementation of the ICU escalation plan in conjunction with the 08:00 meetings can be viewed from two perspectives: internal ICU functioning or management and external communication with the rest of the hospital, emergency and surgery in particular. Table 2 lists the themes and subthemes, along with example quotes.

Within the ICU and management, perceptions of the sustained utility of the ICU escalation plan varied from neutral to very positive. On a practical level, those who found the ICU escalation plan useful identified a variety of mechanisms for this utility including: making it easier to say 'no' when the ICU was at capacity, providing clear reference points for the concept of 'full', which were universal and not linked to bed numbers, facilitating communication with 'higher ups' about patient load and the need to transfer patients and as a basis for more constructive conversations.
Therefore, the plan facilitated improved timing, clarity, unity and positivity in interdepartmental communication. References to current episodes of acute conflict were entirely lacking from the second phase interviews.

Those who found the ICU escalation plan of limited use tended to cite bed block as a major concern. Some pointed out that the plan, and the communication of the ICU status, could have little effect on patient flow at the hospital level and the demands and pressures on the ICU if those external to the ICU did nothing to address patient flow issues. Interestingly, although this critique was intended to be negative, the participants are now thinking in terms of a systems level analysis, rather than a 'silo'-based perspective. In fact, a major theme of the interviews was hospital-wide context and overall patient flow issues. Some participants discussed the pressures they were aware of other teams experiencing, demonstrating an improvement in hospital-wide understanding and cohesion. Some scepticism remained in regards to how other departments functioned and the effect of the political environment on their management. While ED and elective surgery targets were often cited as potentially influencing referrals, it was also suggested that visibility of the ICU could be further improved.

In general, those who felt more positive about the plan were more involved with patient flow management rather than delivering clinical care. Some participants also discussed how the plan provided agreement on current status and gave more structure to decision-making processes within the ICU. This was seen as going some 
Table 2 Phase 2 themes and subthemes

\begin{tabular}{ll}
\hline Theme & Subtheme \\
\hline Internal & Improved \\
communication & decision making
\end{tabular}

Example quotes

communication decision making

'I think by reducing the ad hoc nature of the decisions that makes it clearer. I think any - you know the old good fences make good neighbours. I think it helps from that perspective. I think it probably has improved our workflow. Not so much the morning meeting but the people having an idea about our bed state has improved our workflow to some degree and that helps - then they can say yes we're going to go ahead with all the surgery or we're going to can all the surgery. .... We had in the past where individual surgeons would come marching up and say well, I want to do my case. That's gone away, which is a very, very good thing'. (Doctor 2)

Increased team 'I think bringing the whole team together and everyone hearing the same thing, and cohesion knowing what elective surgery are and knowing what our bed capacity is - I think is a very useful thing. I think it's been good to incorporate nursing and allied health into that, as well. Just so everyone is on the same page, and in terms of a team building exercise'. (Doctor 1)

'So we have lots of people - like the social worker comes, the speech pathologist - I think that's great. Everyone's on the same page. We never used to have that before'. (AH/nurse 3)

Inbuilt 'I guess it's more of a team environment, multi-disciplinary. I think that's better for the team building patients we look after. So there's more of a team approach. I think communication's a lot practise better. Everyone seems to be on the same page more'. (AH/nurse 4)

'In this unit alone, we have a joint morning meeting at 80 'clock in the morning. That's probably one of the biggest changes that's come into effect in the last year I'd say within the unit, over the 15 years I've been here. Mainly because everyone's involved, everyone knows what's happening. I think by doing that everyone's more confident with each other. That comes down then if things happen in the unit you can rely on people and you know who they are and you know what their skills and qualities and that are too'. (AH/ nurse 5)

Team mental model '... overall I'd say that the ICU is working well. I think they're a really cohesive team. I think the steps they've taken to try and manage that uncertainty, that being a positive thing. I think the actual putting something in place that people can own has helped with the relationship in the team, that's great. I think a lot of this is also around the difficulties of you could get the different decision depending on who was there. So having something they could all own and that people recognise this is how we manage and that the other services understand that, that helps. So I think that's certainly, I'd say they were a cohesive, well functioning team. Yes there's pressure but they manage it well'. (Manager 1)

General hospital Improved system context and patient flow

understanding of ICU staff
Need for improved system understanding from other departments

Improved external relationships
'I guess it's a lot of things. We have departments that have guidelines like ED will have a fourhour guideline to get a patient to a ward. So then they want to push a patient to you because that's their guideline. Rightly so, they're trying to do their job'. (AH/nurse 5)

'Then I think the other thing is, not so much transparency because that's what everybody talks about but, more visibility so that we can understand their challenges and constraints. We're not there to fix them, but also so that they can understand ours. Because sometimes it feels like, when you're in the Emergency Department, for example, you're the fish bowl that everybody can look at but we can't see what anybody else is doing, which is a chip on the Emergency guys' shoulders sometimes, which we also need to drop. But I think it's nice to see the other person's pressures as well'. (Doctor 7)

'Basically what I can say to you is it's communication between the nursing director and the wards that we transfer to. It's just that network we've built up. We've realised the importance of it. It's the traffic light system that's actually helped us see that. When they see that we're at this and we don't have a lot of room to move, they will support us in taking the patients out, rather than bed blocking'. (Manager 3)

ICU, intensive care unit.

way to improving the clarity and visibility of the ICU that flowed on to increasing cooperation with other department and hospital management.
One of the most significant aspects of the team meetings was increased team cohesion. One of the main mechanisms of doing so was through the building of a 


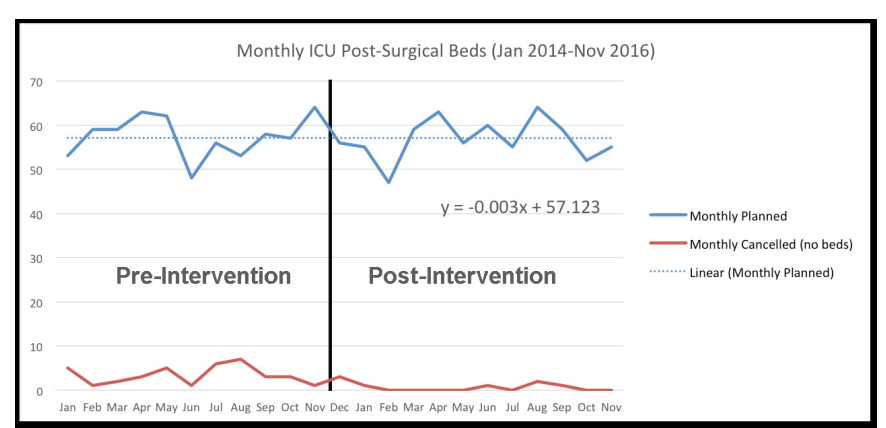

Figure 3 Administrative data. ICU, intensive care unit.

unified mental model in the morning meeting through the use of the escalation plan. Interestingly, this process of needing to agree on a bed status each morning could be seen as a team building exercise in itself. The ICU now start every day with a team negotiation, which brings everyone together and forges a single point of consensus and reduces potential conflict between roles and individuals. This unified position is then both the foundation for all other conversations and interaction within the team for the rest of the day and also presents a unified voice for the team when communicating externally. The creation of a single team mental model has influenced interaction externally as well as communicating a sense of clear ownership and accountability.

\section{Quantitative results}

Administrative data between January 2014 and November 2015 are presented graphically (figure 3 ). The ICU escalation plan commenced operation at the end of November 2014 (figure 3, vertical line). Elements presented are monthly planned surgeries requiring an ICU bed and the number of surgery cancellations each month due to unavailability of an ICU bed. While the number of planned surgeries varied from month to month, the average number of surgeries planned did not markedly increase or decrease over the data collection period (illustrated by the slope of the regression line in figure 3 being close to zero). $\chi^{2}$ comparison of preintervention and postintervention surgery cancellations showed a significant reduction in cancelled surgeries associated with implementation of the intervention, $\mathrm{X}_{1}^{2}=24.9, \mathrm{p}<0.0001$.

Data were also collected on whether the bed status was at 'red', 'amber' or 'green' from the time the intervention commenced at the end of November 2014 until the onsite data collection for the study concluded at the end of August 2015 (figure 4). There were no data for Saturdays or Sundays, as daily meetings did not normally occur,

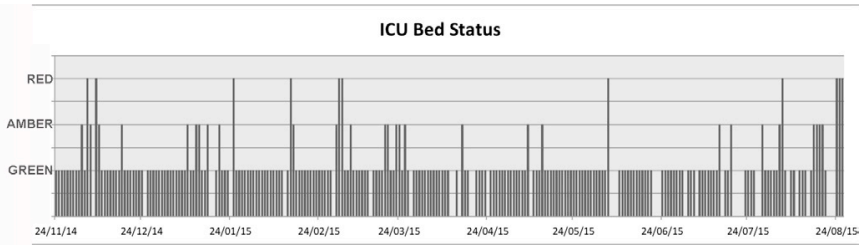

Figure 4 ICU status data. ICU, intensive care unit. and therefore, ICU status was not declared on weekends. Additional administrative data are presented graphically in online appendix 3.

\section{DISCUSSION}

Preintervention, hospital leaders were frustrated with the number of surgeries cancelled by ICU staff, because these surgeries formed part of the NEST and were therefore a critical performance target for the hospital. The immediate response to ICU-initiated surgery cancellations was that more ICU beds were required to solve the patient flow problem and that therefore nothing could be done until more funding was secured. Research in the UK, however, has shown that increasing ICU beds only serves to increases demand. ${ }^{18}$

Using a resilience approach to develop and implement the ICU escalation plan represented a novel approach to reducing conflict and improving function within existing constraints. Early in the implementation, staff within the ICU hoped that the plan would be able to: (1) increase consistency in decision making; (2) make more visible the pressures within ICU; (3) give greater authority to the unit; (4) increase communication within and external to ICU; (5) provide new perspectives; and (6) demonstrate to other departments that the ICU was taking positive measures to reduce conflict. In conjunction with the 08:00 meetings, the plan was also designed to improve the ICU workflow and communication.

These improvements were sustained as the ICU escalation plan evolved, with interviews 7 months postimplementation showing that participants within and external to the ICU still saw the plan as improving workflow and communication. We know from the other studies ${ }^{19}$ that successfully negotiating the boundaries between surgery and the ICU through complex social and cultural interactions among surgeons and ICU clinicians produces collaborative, high-quality patient care. In our study, even those for whom the plan seemed to have limited effect tended to cite some benefits and viewed the problems as system wide constraints, demonstrating a higher level of hospital wide cohesion and a reduction in 'silo' thinking. This was reflected in the major themes of the second interviews which, after communication, were patient flow and general hospital context.

Although other studies have found that teamwork interventions, including bed planning meetings, resulted in improved ICU performance, ${ }^{20}{ }^{21}$ our study is able to provide explanatory detail. Unlike many team building activities, the ICU escalation plan and structure of the morning meetings provided a daily opportunity to practice team skills. Studies on team huddles in healthcare confirm that incorporating opportunities for frequent team building into everyday work can enhance workplace relationships and improve patient safety. ${ }^{22}$ Incorporating teamwork into normal daily activities seems better suited to work as done in healthcare than typical team building activities that can be once off and removed from the 
workplace context. In healthcare, shifts, workload, staff availability and job competence are crucial issues. Team building activities that would require staff to be off-site or occurred only once would likely miss many critical members, not evolve with changing staff over time and therefore dissipate. The morning meetings in ICU were able to capture all new staff, occur without fail, were inclusive of all roles and were socially reinforced. As teamwork improved, the value of the meetings increased, thereby increasing attendance and contribution.

Benefits of the intervention were reflected in the administrative data in terms of reduced surgery cancellations due to unavailability of ICU beds, despite monthly average planned surgeries remaining consistent. It is interesting to note, however, that the ICU status still reached red on occasion after the plan was introduced. It appears from the interview data that, although the bed status was declared red at the morning meeting, rather than cancel surgery, ICU staff worked with the hospital bed planning team to free up ICU beds for when surgery concluded later in the day. A developing awareness of how individual actions can impact system performance suggested that cross-boundary teaming ${ }^{23}$ was developing. In this case, the team did not slavishly follow the plan but instead worked to adapt fluidly across departmental boundaries to meet a system goal. Resilient performance was hence not about strict adherence to rigid rules but in the ability to adapt to emerging conditions.

It was also rare, particularly by early May 2015 when the plan had been in action for a few months, for the ICU to remain on red for more than a single day. This may be an indication that the new process facilitated resilience and rapid recovery from unexpected or challenging events. The daily ICU status provided an additional metric that: (1) gave an indication of proximity to the safety boundary for the unit and (2) allowed more transparency for when extra bed resources were required.

The new ways of working seem likely to be sustainable: during the postintervention interviews, it was not recognised as an intervention but rather accepted as 'how we do things around here'. In some ways, the plan was as much a device to improve cohesion as a plan for improving bed flow. In addition, there was now peer group pressure to attend the 08:00 meeting, as it was a 'norm' for the unit. Therefore, although not everyone liked the ICU escalation plan and morning meetings, no one interviewed suggested their cessation.

By establishing rules for decision making around how beds were allocated in the ICU, the intervention improved internal professional relationships within the ICU as well as between the ICU and external departments. In addition, there was a reduction in the number of elective surgeries cancelled due to unavailability of ICU beds.

\section{Limitations}

While the phase 1 interviews were completed early in the intervention period, when recollections of preintervention behaviours were still fresh, we do not have interview data prior to commencement of the escalation plan, and it is hence possible that the early interviews were coloured by staff experiences during the implementation process. Staff attitudes to the intervention may have also influenced their perceptions of its efficacy. In addition, other drivers of patient demand for ICU beds, such as emergency department factors, were not considered as part of our study, and we did not include the patient voice. Data from a single ICU case, particularly where the intervention was tailored to address the specific problems encountered by that ICU, may limit the generalisability of the findings. The chosen methodology, however, where behaviour is researched along with quantitative outcome data, facilitates a deeper understanding of why the intervention worked. This understanding may be used to translate findings to other hospital environments.

Contributors RC-W, PL, SS and AJ contributed to the conception and design of the study; RC-W and BB collected, analysed and interpreted the study data; RC-W and $\mathrm{BB}$ drafted the manuscript, and PL, SS and AJ revised it critically for intellectual content; all authors approved the final version of the paper.

Funding Financial support for this study was provided in part by a small grant from the Townsville Hospital and Health Service Research Trust Fund. The funding agreement ensured the authors' independence in designing the study, interpreting the data, writing and publishing the report.

Competing interests PL, SS and AJ were involved in development of the intervention; however, they were not interviewed as part of the study and were not involved in data collection or analysis. The authors have no other competing interests to declare.

Patient consent for publication Not required.

Ethics approval Ethics approval for the study was obtained from XX Human Research Ethics Committee (HREC/14/QTHS/117).

Provenance and peer review Not commissioned; externally peer reviewed.

Data sharing statement Data available from the corresponding author on request.

Open access This is an open access article distributed in accordance with the Creative Commons Attribution Non Commercial (CC BY-NC 4.0) license, which permits others to distribute, remix, adapt, build upon this work non-commercially, and license their derivative works on different terms, provided the original work is properly cited, appropriate credit is given, any changes made indicated, and the use is non-commercial. See: http://creativecommons.org/licenses/by-nc/4.0/.

\section{REFERENCES}

1. Reddy $\mathrm{S}$, Jones $\mathrm{P}$, Shanthanna $\mathrm{H}$, et al. A Systematic review of the impact of healthcare reforms on access to Emergency Department and Elective Surgery Services: 1994-2014. International Journal of Health Services 2017:0020731417722089.

2. Siciliani L, Moran V, Borowitz M. Measuring and comparing health care waiting times in OECD countries. Health Policy 2014;118:292-303.

3. Ballini L, Negro A, Maltoni S, et al. Interventions to reduce waiting times for elective procedures. Cochrane Database Syst Rev 2015:CD005610.

4. New South Wales Agency for Clinical Innovation. National Elective Surgery Targets (NEST). 2014 https://www.aci.health.nsw.gov. au/resources/surgical-services/delivery/predictable-surgery/10 (accessed 20 June 2018).

5. Australian Institute of Health and Welfare. Australian hospital statistics (2016-2017): elective surgery waiting times. 2018 https:// www.aihw.gov.au/reports/hospitals/ahs-2016-17-elective-surgerywaiting-times/contents/table-of-contents (Accessed 20 Jun 2018).

6. Etzioni DA, Liu JH, Maggard MA, et al. The aging population and its impact on the surgery workforce. Ann Surg 2003;238:170-7.

7. Adhikari NK, Fowler RA, Bhagwanjee S, et al. Critical care and the global burden of critical illness in adults. Lancet 2010;376:1339-46.

8. Tarnow-Mordi WO, Hau C, Warden A, et al. Hospital mortality in relation to staff workload: a 4-year study in an adult intensive-care unit. The Lancet 2000;356:185-9. 
9. Neuraz A, Guérin C, Payet C, et al. Patient mortality is associated with staff resources and workload in the ICU: a multicenter observational study. Crit Care Med 2015;43:1587-94.

10. Gillies MA, Wijeysundera DN, Harrison EM. Counting the cost of cancelled surgery: a system wide approach is needed. $\mathrm{Br} \mathrm{J}$ Anaesth 2018;121:691-4.

11. Wong DJN, Harris SK, Moonesinghe SR, et al. Cancelled operations: a 7-day cohort study of planned adult inpatient surgery in $245 \mathrm{UK}$ National Health Service hospitals. Br J Anaesth 2018;121:730-8.

12. Runciman WB, Hunt TD, Hannaford NA, et al. CareTrack: assessing the appropriateness of health care delivery in Australia. Med J Aust 2012;197:549-50.

13. Cook R, Rasmussen J. "Going solid": a model of system dynamics and consequences for patient safety. Qual Saf Health Care 2005:14:130-4

14. Paries J, Lot N, Rome F, et al. Resilience in Intensive Care Units: the HUG case. In: Hollnagel E, Braithwaite J, Wears R, eds. Resilient health care. UK: Ashgate Publishing Limited, 2013.

15. Hollnagel E, Braithwaite J, Wears R. Resilient health care. Surrey, UK Ashgate Publishing Limited, 2013.

16. Clay-Williams R, Hounsgaard J, Hollnagel E. Where the rubber meets the road: using FRAM to align work-as-imagined with work-as-done when implementing clinical guidelines. Implement Sci 2015;10:125.
17. Denzin NK, Lincoln YS. Strategies of qualitative inquiry. 4th edn. US: Sage, 2013.

18. Sadique Z. An Examination of the Capacity-Utilisation Relationship in United Kingdom (UK) Intensive Care Units (ICUs) Between 20012011. B102 Novel approaches to understand and improve health outcomes UK. ATS Journals:A3700-A00.

19. Conn LG, Haas B, Cuthbertson BH, et al. Communication and Culture in the Surgical Intensive Care Unit: boundary production and the improvement of patient care. Qual Health Res 2016;26:895-906.

20. Jain M, Miller L, Belt D, et al. Decline in ICU adverse events, nosocomial infections and cost through a quality improvement initiative focusing on teamwork and culture change. Qual Saf Health Care 2006;15:235-9.

21. Ryckman FC, Yelton PA, Anneken AM, et al. Redesigning intensive care unit flow using variability management to improve access and safety. Jt Comm J Qual Patient Saf 2009;35:535-43.

22. Provost SM, Lanham HJ, Leykum LK, et al. Health care huddles: managing complexity to achieve high reliability. Health Care Manage Rev 2015;40:2-12.

23. Edmondson AC, Harvey J-F. Cross-boundary teaming for innovation: Integrating research on teams and knowledge in organizations. Human Resource Management Review 2018;28:347-60. 